\title{
Ab initio study of adsorption and diffusion of lithium on transition metal dichalcogenide monolayers
}

\author{
Xiaoli Sun and Zhiguo Wang*
}

\author{
Full Research Paper \\ Address: \\ School of Physical Electronics, University of Electronic Science and \\ Technology of China, Chengdu, 610054, P.R. China \\ Email: \\ Zhiguo Wang* - zgwang@uestc.edu.cn \\ * Corresponding author \\ Keywords: \\ anode materials; lithium adsorption; lithium diffusion; lithium ion \\ batteries; transition metal dichalcogenide
}

Beilstein J. Nanotechnol. 2017, 8, 2711-2718.

doi:10.3762/bjnano.8.270

Received: 02 July 2017

Accepted: 19 November 2017

Published: 15 December 2017

Associate Editor: P. Leiderer

() 2017 Sun and Wang; licensee Beilstein-Institut.

License and terms: see end of document.

\begin{abstract}
Using first principles calculations, we studied the stability and electronic properties of transition metal dichalcogenide monolayers of the type $\mathrm{MX}_{2}(\mathrm{M}=\mathrm{Ti}, \mathrm{Zr}, \mathrm{Hf}, \mathrm{V}, \mathrm{Nb}, \mathrm{Ta}, \mathrm{Mo}, \mathrm{Cr}, \mathrm{W} ; \mathrm{X}=\mathrm{S}, \mathrm{Se}, \mathrm{Te})$. The adsorption and diffusion of lithium on the stable $\mathrm{MX}_{2}$ phase was also investigated for potential application as an anode for lithium ion batteries. Some of these compounds were found to be stable in the $2 \mathrm{H}$ phase and some are in the $1 \mathrm{~T}$ or $1 \mathrm{~T}^{\prime}$ phase, but only a few of them were stable in both $2 \mathrm{H} / 1 \mathrm{~T}$ or $2 \mathrm{H} / 1 \mathrm{~T}^{\prime}$ phases. The results show that lithium is energetically favourable for adsorption on $\mathrm{MX}_{2}$ monolayers, which can be semiconductors with a narrow bandgap and metallic materials. Lithium cannot be adsorbed onto $2 \mathrm{H}-\mathrm{WS}_{2}$ and $2 \mathrm{H}-\mathrm{WSe} \mathrm{e}_{2}$, which have large bandgaps of 1.66 and $1.96 \mathrm{eV}$, respectively. The diffusion energy barrier is in the range between 0.17 and $0.64 \mathrm{eV}$ for lithium on $\mathrm{MX}_{2} \mathrm{mono}^{-}$ layers, while for most of the materials it was found to be around $0.25 \mathrm{eV}$. Therefore, this work illustrated that most of the $\mathrm{MX}_{2}$ monolayers explored in this work can be used as promising anode materials for lithium ion batteries.
\end{abstract}

\section{Introduction}

Lithium ion batteries (LIBs) have been widely used in portable electronic devices as power supplies, which have potential use in electrical vehicles (EVs) and smart grids. However, the energy and power density of current LIBs cannot satisfy the high demand of EVs. The development of new electrode materials is essential for improvement of the energy density. An ideal electrode material for LIBs should have good electronic conductivity, a lower Li diffusion energy barrier, as well as high energy and power densities. By reducing the bulk electrode materials to low-dimensional materials, a higher energy capacity and higher charge/discharge rate can be obtained as the lowdimensional materials have higher exposure to the electrolyte [1]. Two-dimensional materials, such as $\mathrm{Co}_{3} \mathrm{O}_{4}, \mathrm{NiO}$, phosphorene, $\mathrm{SnS}$ and $\mathrm{V}_{2} \mathrm{O}_{5}$ all exhibit an excellent capacity retention, rate performance, lower energy barrier and long cycling life compared to their bulk counterparts used as electrode materials for LIBs [2-8].

Two-dimensional transition metal dichalcogenides, $\mathrm{MX}_{2}$ (where $\mathrm{M}$ and $\mathrm{X}$ correspond to transition metal and chalcogen atoms, 
respectively), have been synthesized using different strategies, such as exfoliation [9,10], physical vapour deposition [11] and chemical vapour deposition [12-14]. $\mathrm{MX}_{2}$ has received tremendous attention as an alternative to graphite for the anode material in LIBs $[15,16]$. In particular, $\mathrm{MoS}_{2}$ has been well-investigated as an anode material for LIBs both theoretically and experimentally. A graphene like- $\mathrm{MoS}_{2} /$ graphene composite was shown to exhibit a high specific capacity of $1400 \mathrm{~mA} \mathrm{~h} / \mathrm{g}$ and good rate performance as well as cycling ability [17]. It was reported that $\mathrm{MoS}_{2}$ zigzag nanoribbons are promising electrode materials for LIBs with a high power density and fast charge/ discharge rates [18]. The presence of structural defects can enhance the adsorption of $\mathrm{Li}$ atoms onto two-dimensional materials. Different from the situation where Li atoms are trapped by the defects in graphene, the presence of structural defects does not affect the diffusion of lithium [19]. The main drawback of $\mathrm{MoS}_{2}$ is its poor electrical conductivity. Various strategies have been developed to improve the electrochemical properties of $\mathrm{MoS}_{2}$ as an anode for LIBs. Three-dimensional hierarchical structures constructed by assembling two-dimensional $\mathrm{MoS}_{2}$ nanosheets can deliver a capacity of $1009 \mathrm{mAh} / \mathrm{g}$ at $500 \mathrm{~mA} / \mathrm{g}$ after 500 cycles [20]. The formation of composites of $\mathrm{MoS}_{2}$ with other materials, such as carbon-based materials and noncarbonaceous materials, can enhance the electromechanical properties of $\mathrm{MoS}_{2}$. Wang et al. [21] utilized a beneficial "bridging effect" of sulfur atoms to bind few-layered $\mathrm{MoS}_{2}$ with graphene, which provided fast electron conductivity and excellent cycling stability and superior rate performance. The composites exhibited a high discharge capacity of $1546 \mathrm{mAh} / \mathrm{g}$ after 300 cycles. The $\mathrm{MoS}_{2}$ composites grown on $\mathrm{TiO}_{2}$ nanotubes show better rate capability with a reversible capacity of $461 \mathrm{mAh} / \mathrm{g}$ at $1000 \mathrm{~mA} / \mathrm{g}$, compared with the capacity of pure $\mathrm{MoS}_{2}(129 \mathrm{mAh} / \mathrm{g})$ at the same current density [22].

$\mathrm{MX}_{2}$ monolayers have three types of crystalline structures, hexagonal structure $(2 \mathrm{H})$, octahedral structure $(1 \mathrm{~T})$ and distorted octahedral structure $\left(1 \mathrm{~T}^{\prime}\right)$ [23-25]. The structures depend on the arrangements of the $\mathrm{M}$ and $\mathrm{X}$ atoms. Phase transformation between the different phases occurs during the synthesis process and lithium/sodium intercalation [26-28]. Sun et al. [29] have studied the effect of electron doping on the stability of $2 \mathrm{H}$ - and $1 \mathrm{~T}^{\prime}-\mathrm{MoS}_{2}$, and showed that electron doping can stabilize the crystal structure of $1 \mathrm{~T}^{\prime}-\mathrm{MoS}_{2}$. The crystalline structure can also affect the energy conversion efficiency, for example in the hydrogen evolution reaction (HER). The basal plane of $2 \mathrm{H}-\mathrm{MoS}_{2}$ is inert [30], where that of $1 \mathrm{~T}^{\prime}-\mathrm{MoS}_{2}$ is catalytically active for HER [31]. Until now, there is no systematic study on the family of transition metal dichalcogenide monolayers used as anode for LIBs.

In this work, we studied the stability of $\mathrm{MX}_{2}$ monolayers, and the adsorption and diffusion of $\mathrm{Li}$ on the stable $\mathrm{MX}_{2}$ monolayers $(\mathrm{M}=\mathrm{Ti}, \mathrm{Zr}, \mathrm{Hf}, \mathrm{V}, \mathrm{Nb}, \mathrm{Ta}, \mathrm{Mo}, \mathrm{Cr}, \mathrm{W} ; \mathrm{X}=\mathrm{S}, \mathrm{Se}, \mathrm{Te})$. These results are helpful for the design of two-dimensional transition metal dichalcogenide based electrodes for LIBs.

\section{Results and Discussion}

We systematically investigated the phase stability, Li adsorption and diffusion on $\mathrm{MX}_{2}$ monolayers $(\mathrm{M}=\mathrm{Ti}, \mathrm{Zr}, \mathrm{Hf}, \mathrm{V}, \mathrm{Nb}$, $\mathrm{Ta}, \mathrm{Cr}, \mathrm{Mo}, \mathrm{W} ; \mathrm{X}=\mathrm{S}, \mathrm{Se}, \mathrm{Te})$. The combination of these elements have twenty seven possible binary compound materials. Three phases, including $2 \mathrm{H}, 1 \mathrm{~T}$ and $1 \mathrm{~T}^{\prime}$ structures, were all considered for each of the binary monolayers. All the three structures can be viewed as a positively charged, two-dimensional $\mathrm{M}$ atoms, lattice-sandwiched by two hexagonal lattices of negatively charged $\mathrm{X}$ atoms. Each $\mathrm{M}$ atom is surrounded by six nearest $\mathrm{X}$ atoms, and each $\mathrm{X}$ atom is connected to three nearest $\mathrm{M}$ atoms with ionic $\mathrm{M}-\mathrm{X}$ bonds. The side and cross-views of the ball and stick models of the $\mathrm{MX}_{2}$ monolayer are shown in Figure 1. The $\mathrm{M}$ atoms are located at the lattice positions of a hexagonal close-packed structure with a trigonal symmetry in the $2 \mathrm{H}-\mathrm{MX}_{2}$ phase (Figure 1a), whereas $\mathrm{M}$ atoms are located at

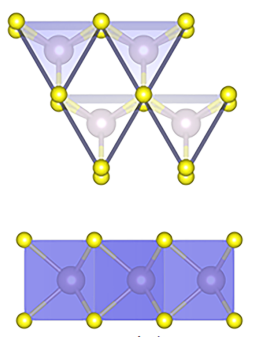

(a)
8
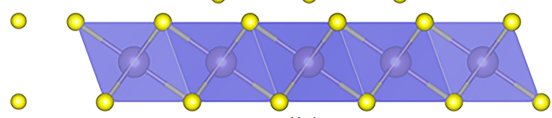

(b)

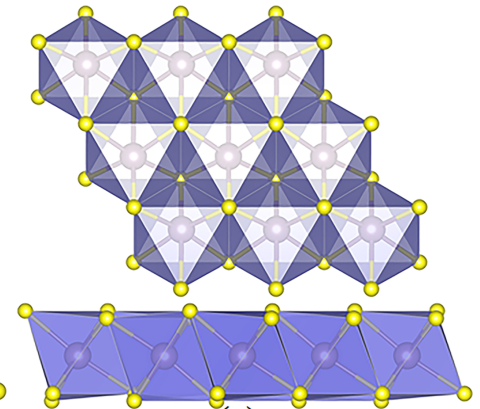

(c)

Figure 1: Top and side views of ball and stick models of a $\mathrm{MX}_{2}$ monolayer in (a) $2 \mathrm{H}$, (b) $1 \mathrm{~T}$ and (c) $1 \mathrm{~T}$ ' phase. The $\mathrm{M}$ atoms have octahedral and trigonal prismatic coordination in the $1 \mathrm{~T} / 1 \mathrm{~T}^{\prime}$ and $2 \mathrm{H}$ phase, respectively. 
the octahedral/disordered octahedral centre of six S atoms in the $1 \mathrm{~T} / 1 \mathrm{~T}^{\prime}$ phase (Figure 1b,c). Some compounds are not stable in the $1 \mathrm{~T}^{\prime}$ phase, which will be relaxed to the $1 \mathrm{~T}$ phase after relaxation.

The energy related to the $2 \mathrm{H}$ phase per formula unit (f.u.), $E=E_{1 \mathrm{~T} / 1 \mathrm{~T}^{\prime}}-E_{2 \mathrm{H}}$, is listed in Table 1. A negative value indicates that the $1 \mathrm{~T} / 1 \mathrm{~T}^{\prime}$ phase is more stable than the $2 \mathrm{H}$ phase. It can be seen from the table that some of these compound can be stable in the $2 \mathrm{H}$ phase, and some in the $1 \mathrm{~T}$ or $1 \mathrm{~T}^{\prime}$ phase. Only a few of them are stable both in $2 \mathrm{H} / 1 \mathrm{~T}$ or $2 \mathrm{H} / 1 \mathrm{~T}^{\prime}$ phases. The $2 \mathrm{H}$ phase is the minimum energy configuration for monolayers of $\mathrm{NbX}_{2}$ and $\mathrm{TaX}_{2}$, which agrees with previously reported results $[32,33]$. The energy of the $1 \mathrm{~T}$ phase is smaller than the $2 \mathrm{H}$ phase for $\mathrm{TiX}_{2}, \mathrm{VX}_{2}, \mathrm{VSe}_{2}, \mathrm{CrX}_{2}, \mathrm{ZrX}_{2}$ and $\mathrm{HfX}_{2}$. 1T-VS monolayers are $0.02 \mathrm{eV} / \mathrm{f}$.u. larger than the $2 \mathrm{H}$ phase, which indicates that the $1 \mathrm{~T}$ phase is the energetically favourable one for these compounds, and $\mathrm{VS}_{2}$ monolayers maybe be stable both in the $2 \mathrm{H} / 1 \mathrm{~T}$ phase. The results agree with other calculations that imply that the $1 \mathrm{~T}$ phase is more stable than $2 \mathrm{H}$ in $\mathrm{TiX}_{2}$ [3234], $\mathrm{CrS}_{2}$ [35], $\mathrm{ZrX}_{2}$ [32,33] and $\mathrm{HfX}_{2}$ [33]. The $2 \mathrm{H}$ phase is the stable structure for $\mathrm{MoS}_{2}, \mathrm{MoSe}_{2}, \mathrm{WS}_{2}$ and $\mathrm{WSe}_{2}$ monolayers, which has also been predicted by other simulations [3640]. $1 \mathrm{~T}^{\prime}-\mathrm{VTe}_{2}, 1 \mathrm{~T}^{\prime}-\mathrm{MoTe}_{2}$ and $1 \mathrm{~T}^{\prime}-\mathrm{WTe} \mathrm{T}_{2}$ are the energetically favourable phases. It is also can be seen from Table 1 that $1 \mathrm{~T}^{\prime}-$ $\mathrm{MoTe}_{2}$ is $0.06 \mathrm{eV} /$ f.u. more energetically favourable than the $1 \mathrm{~T}$ phase, which agrees with other simulations $[36,39,40]$. The energy difference between $2 \mathrm{H}-\mathrm{WTe}_{2}$ and $1 \mathrm{~T}^{\prime}-\mathrm{WTe}_{2}$ is $0.07 \mathrm{eV} /$ f.u., which indicates $\mathrm{MoTe}_{2}$ and $\mathrm{WTe}_{2}$ maybe exist in two phases.

The calculated lattice constants and bond length of the M-X bond in the stable phase is listed in Table 2 along with available values from other simulations. The values obtained in the present work agree well with other simulation results. It can be seen from Table 2 that lattice constants and bond lengths increase for the all the $\mathrm{MX}_{2}$ monolayers as the element $\mathrm{X}$ changes from $\mathrm{S}$ to Te in group VI for a given element $\mathrm{M}$. The variation can be explained by the increasing atomic radius of elements $\mathrm{X}$ from $\mathrm{S}$ to Te.

The band structures of $\mathrm{MX}_{2}$ monolayers in the stable phase are shown in Figure 2. The $\mathrm{MX}_{2}$ monolayers can be semiconducting with a direct and indirect bandgap or metallic materials. The electronic conductive behaviour of these compounds are shown in Table 2 . The $2 \mathrm{H}$ phase shows a semiconducting behaviour, such as $2 \mathrm{H}-\mathrm{WX}_{2}, 2 \mathrm{H}-\mathrm{NbX} 2,2 \mathrm{H}-\mathrm{TaX}_{2}$ and $2 \mathrm{H}-\mathrm{MoX}_{2}$. The $1 \mathrm{~T}$ phase can be metallic or semiconducting, such as in $1 \mathrm{~T}-\mathrm{VX}_{2}(\mathrm{X}=\mathrm{S}, \mathrm{Se})$, and $1 \mathrm{~T}-\mathrm{CrX} \mathrm{X}_{2}$ shows metallic behaviour, while $1 \mathrm{~T}-\mathrm{TiX}_{2}, 1 \mathrm{~T}-\mathrm{ZrX}_{2}$ and $1 \mathrm{~T}-\mathrm{HfX}_{2}$ show semiconducting and metallic behaviour with $\mathrm{X}=\mathrm{S} / \mathrm{Se}$ and $\mathrm{X}=\mathrm{Te}$, respectively. $1 \mathrm{~T}^{\prime}-\mathrm{VTe}_{2}$ and $1 \mathrm{~T}^{\prime}-\mathrm{MoTe}_{2}$ show metallic behaviour and $1 \mathrm{~T}^{\prime}-$ $\mathrm{WTe}_{2}$ has a narrow bandgap of $0.50 \mathrm{eV}$. The obtained bandgap values are close to those previously reported for $\mathrm{TiS}_{2}$ [32], $\mathrm{CrTe}_{2}$ [40], $\mathrm{TiX}_{2}$ [32,33,47], MoX 2 [33,40,47,50-55], $\mathrm{HfX}_{2}$ $[33,47]$ and $\mathrm{WX}_{2}[33,40,47,50,55-58]$. The metallic $\mathrm{MX}_{2}$ monolayers have good electrical conductivity, which may make them good anode materials.

As shown in Figure 3a and Figure 3b, there are two stable adsorption sites, that is, the hollow site $(\mathrm{H})$ and the top position above the $\mathrm{M}$ atom $(\mathrm{T})$ for $\mathrm{Li}$ to be adsorbed on the $2 \mathrm{H}$ - and $1 \mathrm{~T}-\mathrm{MX}_{2}$ monolayers [18]. Four adsorption sites (T1, T2, H1, and $\mathrm{H} 2$ ) are considered for $\mathrm{Li}$ adsorption onto the $1 \mathrm{~T}^{\prime}-\mathrm{MX}_{2}$ monolayer, as shown in Figure 3c. To analyse the stability of $\mathrm{Li}$ adsorbed on the $\mathrm{MX}_{2}$ monolayers, the adsorption energy, $E_{\text {ad }}(\mathrm{Li})$, is calculated using Equation 1:

$$
E_{\mathrm{ad}}(\mathrm{Li})=E_{\mathrm{MX}_{2}+\mathrm{Li}}-E_{\mathrm{MX}_{2}}-E_{\mathrm{Li}}
$$

where $E_{\mathrm{MX} 2+\mathrm{Li}}$ and $E_{\mathrm{MX} 2}$ are the total energy of the $\mathrm{MX}_{2}$ monolayer with and without $\mathrm{Li}$ adsorption, respectively. $E_{\mathrm{Li}}$ is the energy of a Li atom in bulk material. The calculated adsorp-

\begin{tabular}{|c|c|c|c|c|c|c|c|c|c|}
\hline \multirow[t]{2}{*}{ M } & \multicolumn{3}{|c|}{$S$} & \multicolumn{3}{|c|}{$\mathrm{Se}$} & \multicolumn{3}{|c|}{$\mathrm{Te}$} \\
\hline & $2 \mathrm{H}$ & $1 \mathrm{~T}$ & $1 \mathrm{~T}^{\prime}$ & $2 \mathrm{H}$ & $1 \mathrm{~T}$ & $1 \mathrm{~T}^{\prime}$ & $2 \mathrm{H}$ & $1 \mathrm{~T}$ & $1 \mathrm{~T}^{\prime}$ \\
\hline $\mathrm{Ti}$ & 0.00 & -0.44 & - & 0.00 & -0.33 & - & 0.00 & -0.26 & - \\
\hline V & 0.00 & 0.02 & - & 0.00 & -0.16 & - & 0.00 & -0.06 & -0.15 \\
\hline $\mathrm{Cr}$ & 0.00 & -0.45 & - & 0.00 & -0.39 & - & 0.00 & -0.17 & - \\
\hline $\mathrm{Zr}$ & 0.00 & -0.54 & - & 0.00 & -0.40 & - & 0.00 & -0.26 & - \\
\hline $\mathrm{Nb}$ & 0.00 & 0.21 & - & 0.00 & 0.22 & - & 0.00 & 0.15 & 0.10 \\
\hline Mo & 0.00 & 0.68 & 0.60 & 0.00 & 0.35 & 0.29 & 0.00 & -0.20 & -0.26 \\
\hline $\mathrm{Hf}$ & 0.00 & -0.62 & - & 0.00 & -0.50 & - & 0.00 & -0.35 & - \\
\hline $\mathrm{Ta}$ & 0.00 & 0.18 & - & 0.00 & 0.23 & 0.21 & 0.00 & 0.15 & 0.54 \\
\hline W & 0.00 & 0.91 & 0.61 & 0.00 & 0.81 & 0.35 & 0.00 & 0.61 & -0.07 \\
\hline
\end{tabular}


Table 2: Lattice constants $(a, b)$ and the bond length of the $\mathrm{M}-\mathrm{X}$ bond $\left(d_{\mathrm{M}-\mathrm{X}}\right)$ in the stable phase as calculated in this work as compared to other values found in the literature from other simulations. The electronic conducting behaviour (ECB) of these compounds is also shown.

\begin{tabular}{|c|c|c|c|c|c|}
\hline $\mathrm{MX}_{2}$ & $a / b(\AA)$ & $d_{M-X}(\AA)$ & $a(\AA)$ [Ref.] & $d_{M-X}(\AA)[$ Ref.] & $\mathrm{ECB}$ \\
\hline $1 \mathrm{~T}-\mathrm{TiS}_{2}$ & 3.40 & 2.42 & 3.39 [33] & 2.39 [41] & 0.59 \\
\hline $1 \mathrm{~T}-\mathrm{TiSe}_{2}$ & 3.56 & 2.57 & 3.53 [33] & $2.51[41]$ & 0.29 \\
\hline $1 \mathrm{~T}-\mathrm{TiTe}_{2}$ & 3.72 & 2.77 & 3.74 [33] & $2.73[41]$ & metal \\
\hline $2 \mathrm{H}-\mathrm{VS}_{2}$ & 3.19 & 2.39 & 3.17 [42-44] & $2.36[42-44]$ & 0.58 \\
\hline $1 \mathrm{~T}-\mathrm{VS} \mathrm{S}_{2}$ & 3.25 & 2.38 & $3.18[43,45]$ & $2.35[43,44,46]$ & metal \\
\hline $1 \mathrm{~T}-\mathrm{VSe} \mathrm{S}_{2}$ & 3.37 & 2.55 & 3.24 [41] & $2.49[46]$ & metal \\
\hline $1 \mathrm{~T}^{\prime}-\mathrm{VTe} \mathrm{e}_{2}$ & $\begin{array}{l}3.80 / \\
7.60\end{array}$ & $\begin{array}{l}2.71 / \\
2.76 / \\
2.79 / \\
2.81\end{array}$ & - & - & metal \\
\hline $1 \mathrm{~T}-\mathrm{CrS}_{2}$ & 3.33 & 2.41 & - & - & metal \\
\hline $1 \mathrm{~T}-\mathrm{CrSe}{ }_{2}$ & 3.47 & 2.56 & - & - & metal \\
\hline $1 \mathrm{~T}-\mathrm{CrTe}_{2}$ & 3.67 & 2.81 & - & - & metal \\
\hline $1 \mathrm{~T}-\mathrm{ZrS}_{2}$ & 3.57 & 2.55 & $3.68[33,47]$ & & 0.92 \\
\hline $1 \mathrm{~T}-\mathrm{ZrSe}{ }_{2}$ & 3.70 & 2.68 & $3.79[47]$ & & 0.29 \\
\hline $1 \mathrm{~T}-\mathrm{ZrTe} \mathrm{T}_{2}$ & 3.89 & 2.90 & 3.98 [33] & & metal \\
\hline $2 \mathrm{H}-\mathrm{NbS}_{2}$ & 3.35 & 2.50 & 3.36 [48] & $2.49[48]$ & 1.22 \\
\hline $2 \mathrm{H}-\mathrm{NbSe}{ }_{2}$ & 3.49 & 2.64 & $3.48[48]$ & $2.62[48]$ & 1.00 \\
\hline $2 \mathrm{H}-\mathrm{NbTe}_{2}$ & 3.71 & 2.83 & $3.70[48]$ & $2.82[48]$ & 0.78 \\
\hline $2 \mathrm{H}-\mathrm{MoS}_{2}$ & 3.17 & 2.42 & $3.18[47,49]$ & $2.42[48]$ & 1.71 \\
\hline $2 \mathrm{H}-\mathrm{MoSe}_{2}$ & 3.32 & 2.55 & $3.32[47]$ & $2.55[48]$ & 1.41 \\
\hline $1 \mathrm{~T}-\mathrm{MoTe}_{2}$ & 3.84 & 2.81 & - & - & metal \\
\hline $1 \mathrm{~T}^{\prime}-\mathrm{MoTe}_{2}$ & $\begin{array}{l}3.89 / \\
7.88\end{array}$ & $\begin{array}{l}2.53 / \\
2.55 / \\
2.60 / \\
2.61\end{array}$ & - & - & 0.12 \\
\hline $1 \mathrm{~T}-\mathrm{HfS}_{2}$ & 3.57 & 2.54 & 3.64 [33] & - & 1.09 \\
\hline $1 \mathrm{~T}-\mathrm{HfSe} e_{2}$ & 3.69 & 2.67 & 3.76 [33] & - & 0.50 \\
\hline 1T-HfTe 2 & 3.88 & 2.87 & 3.97 [33] & - & metal \\
\hline $2 \mathrm{H}-\mathrm{TaS}_{2}$ & 3.35 & 2.50 & 3.34 [48] & $2.48[48]$ & 0.20 \\
\hline $2 \mathrm{H}-\mathrm{TaSe}_{2}$ & 3.47 & 2.63 & 3.48 [48] & $2.62[48]$ & 0.46 \\
\hline $2 \mathrm{H}-\mathrm{TaTe}_{2}$ & 3.69 & 2.82 & 3.76 [48] & $2.82[48]$ & 0.37 \\
\hline $2 \mathrm{H}-\mathrm{WS}_{2}$ & 3.18 & 2.44 & 3.18 [49] & $2.42[48]$ & 1.96 \\
\hline $2 \mathrm{H}-\mathrm{WSe}_{2}$ & 3.32 & 2.57 & $3.32[47,48]$ & 2.55 [48] & 1.66 \\
\hline $2 \mathrm{H}-\mathrm{WTe}_{2}$ & 3.56 & 2.76 & - & - & 1.22 \\
\hline $1 T^{\prime}-W T e_{2}$ & $\begin{array}{l}3.49 / \\
6.98\end{array}$ & $\begin{array}{l}2.74 / \\
2.75 / \\
2.78 / \\
2.81\end{array}$ & - & - & 0.38 \\
\hline
\end{tabular}

tion energy of $\mathrm{Li}$ on the stable phase of the $\mathrm{MX}_{2}$ monolayers is shown in Figure 4. The adsorption energy has positive values for $\mathrm{Li}$ adsorbed on $2 \mathrm{H}-\mathrm{WS}_{2}$ and $2 \mathrm{H}-\mathrm{WSe}_{2}$, which indicates that Li cannot be adsorbed on these two compounds and they are not ideal anodes for LIBs. The other compounds have negative values of adsorption energy. The adsorption energy of $\mathrm{Li}$ on $2 \mathrm{H}-\mathrm{MoS}_{2}$ is -0.05 and $-0.25 \mathrm{eV}$ for $\mathrm{H}$ and $\mathrm{T}$ sites, respectively. The materials will have a large energy storage capacity if they have a large exothermic reaction energy with $\mathrm{Li}$ [19]. Previous studies have shown that the $2 \mathrm{H}-\mathrm{MoS}_{2}$ monolayer is a good anode material for LIBs [26-28]. The absolute value of the adsorption energy for Li adsorbed on other compounds is larger than that of $2 \mathrm{H}-\mathrm{MoS}_{2}$, so other $\mathrm{MX}_{2}$ compounds are also good anode candidates for LIBs. The adsorption energy as a function of the bandgap of the $\mathrm{MX}_{2}$ monolayer is show in Figure 4. It can also be seen from the figure that $\mathrm{MX}_{2}$ is a semiconducting material with a narrow bandgap, and for metallic materials, the adsorption energy has larger negative values. The materials with a large bandgap have smaller adsorption energy, even those with positive values. For example, the bandgap energies are $1.96,1.71,0.78,0.58$ and $0.29 \mathrm{eV}$ and the adsorption energies for $\mathrm{Li}$ adsorbed at $\mathrm{H} / \mathrm{T}$ sites are $0.37 / 0.24,-0.05 /-0.25$, 

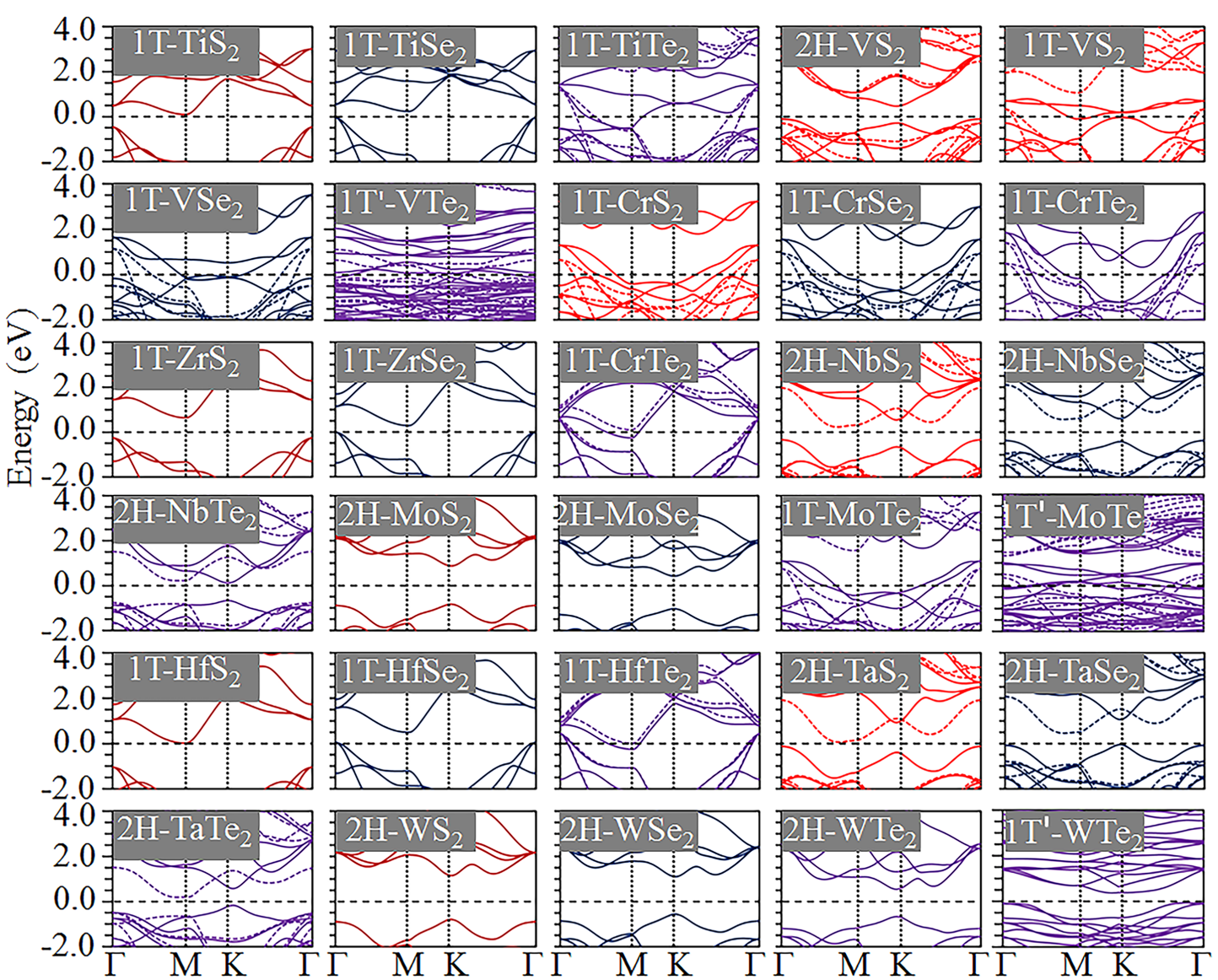

Figure 2: Band structures of $M X_{2}$ monolayers in the stable phase. Fermi energy level is set to be 0 .

$-0.51 /-0.65,-1.79 / 1.87$ and $-2.08 / 2.07 \mathrm{eV}$ on $2 \mathrm{H}-\mathrm{WS}_{2}$, $2 \mathrm{H}-\mathrm{MoS}_{2}, 2 \mathrm{H}-\mathrm{NbTe}_{2}, 2 \mathrm{H}-\mathrm{VS}_{2}$ and $1 \mathrm{~T}-\mathrm{TiSe}_{2}$ monolayers, respectively.

The diffusion of $\mathrm{Li}$ on the $\mathrm{MX}_{2}$ monolayers is through the $\mathrm{T} \rightarrow \mathrm{H} \rightarrow \mathrm{T}$ and $\mathrm{T} 1 \rightarrow \mathrm{H} 1 \rightarrow \mathrm{T} 2 \rightarrow \mathrm{H} 2 \rightarrow \mathrm{T} 1$ paths for the $2 \mathrm{H} / 1 \mathrm{~T}$ and $1 \mathrm{~T}^{\prime}$ phases, respectively [59], as shown in Figure $3 \mathrm{a}-\mathrm{c}$. The typical diffusion energy profiles are shown in Figure $3 \mathrm{~d}$, Figure $3 \mathrm{e}$ and Figure $3 \mathrm{f}$ for $\mathrm{Li}$ on $2 \mathrm{H}-\mathrm{MoS}_{2}, 1 \mathrm{~T}-\mathrm{TiS}_{2}$, and $1 \mathrm{~T}^{\prime}$ $\mathrm{MoTe}_{2}$ monolayers, respectively. The constrained method was used to evaluate the diffusion behaviour of $\mathrm{Li}$ on $\mathrm{MX}_{2}$ monolayers - this method is more simple and intuitive compared to the nudged elastic band method and dimer method [60]. The diffusion energy barriers are $0.29,0.25$ and $0.28 \mathrm{eV}$ for $\mathrm{Li}$ on $2 \mathrm{H}-\mathrm{MoS}_{2}, 1 \mathrm{~T}-\mathrm{TiS}_{2}$, and $1 \mathrm{~T}^{\prime}-\mathrm{MoTe}_{2}$ monolayers, respectively. These values are reasonable for use as anodes for LIBs. The Li diffusion energy barrier on a $\mathrm{MX}_{2}$ monolayer is shown in Figure 4. Our calculated values agree well with those reported by other researchers. The diffusion energy barrier for $\mathrm{Li}$ on the $2 \mathrm{H}$ phase of monolayer $\mathrm{WS}_{2}, \mathrm{WSe}_{2}$ and $\mathrm{VS}_{2}$ is $0.21 \mathrm{eV}$, $0.18 \mathrm{eV}$ and $0.20 \mathrm{eV}$, respectively, which is consistent with the previously reported values of $0.22,0.23 \mathrm{eV}$ [61], and $0.22 \mathrm{eV}$
[42] respectively. The diffusion energy barrier of $\mathrm{Li}$ on $2 \mathrm{H}-\mathrm{MoS}_{2}$ monolayer is $0.29 \mathrm{eV}$, which is consistent with the previously reported value of $0.25 \mathrm{eV}[18,42]$.

A good anode material should have a high electron and $\mathrm{Li}$ mobility and a large exothermic reaction energy with lithium. High electronic and ion mobility determine the rate capability and cycling performance, and a large exothermic reaction energy indicates the anode materials have a large energy storage capacity. The diffusion energy barrier is in the range between 0.17 and $0.63 \mathrm{eV}$, and most are around $0.25 \mathrm{eV}$, which indicates that all the $\mathrm{MX}_{2}$ monolayers have a reasonable diffusion energy barrier for lithium. The metallic $\mathrm{MX}_{2}$ monolayers and those with small bandgaps have a large adsorption energy for $\mathrm{Li}$, which indicates that they are good anode materials for LIBs with high electronic and ion mobility and large energy storage capacity.

\section{Conclusion}

Using density functional theory (DFT) simulations, the stability and electronic properties of $\mathrm{MX}_{2}$ monolayers were investigated. $\mathrm{TiX}_{2}, \mathrm{VSe}_{2}, \mathrm{CrX}_{2}, \mathrm{ZrX}_{2}$ and $\mathrm{HfX}_{2}$ are energetically favourable 

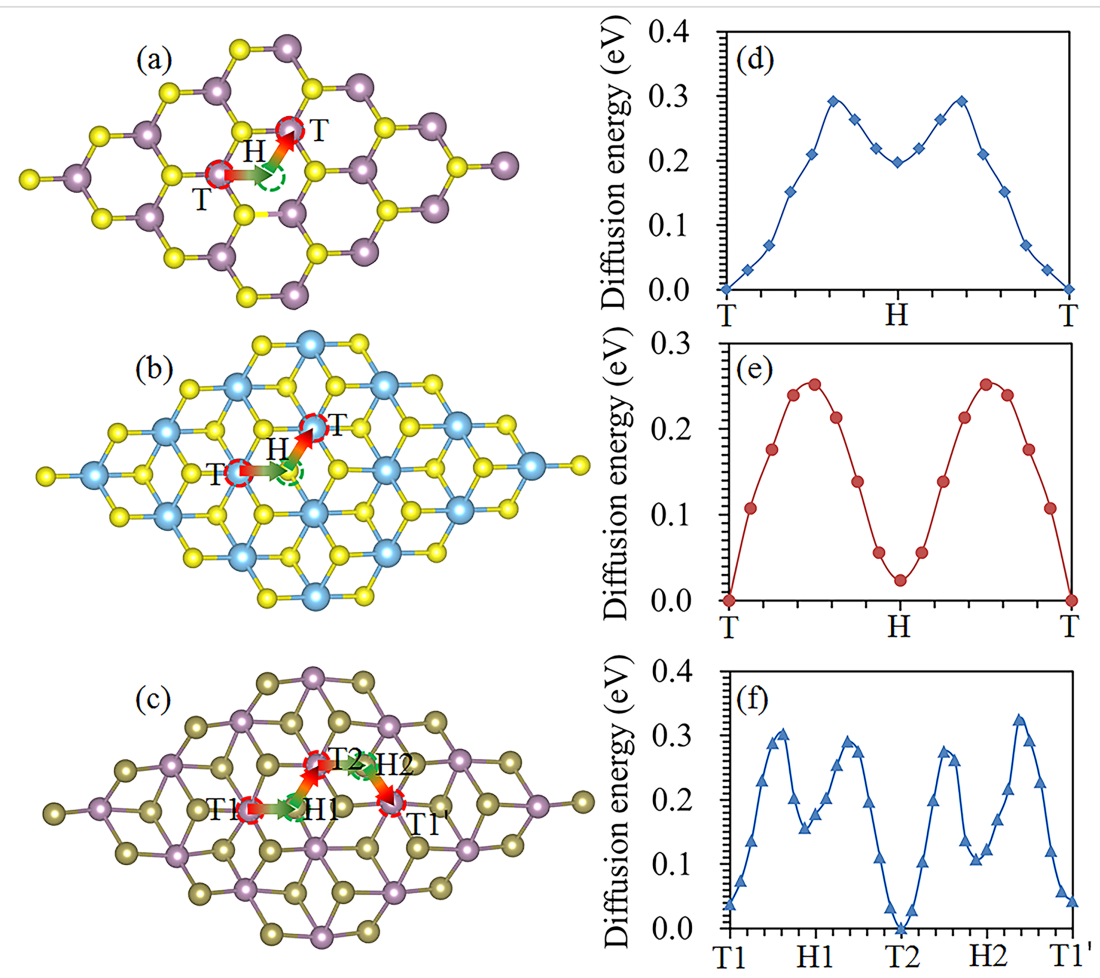

Figure 3: Possible adsorption sites and diffusion paths for $\mathrm{Li}$ on a monolayer of (a) $2 \mathrm{H}-$, (b) $1 \mathrm{~T}$ - and (c) $1 \mathrm{~T}^{\prime}-\mathrm{MX}_{2}$. Diffusion energy profiles for $\mathrm{Li}$ on (d) $2 \mathrm{H}-\mathrm{MoS}_{2}$, (e) $1 \mathrm{~T}-\mathrm{TiS}_{2}$, and (f) $1 \mathrm{~T}^{\prime}-\mathrm{MoTe}_{2}$.

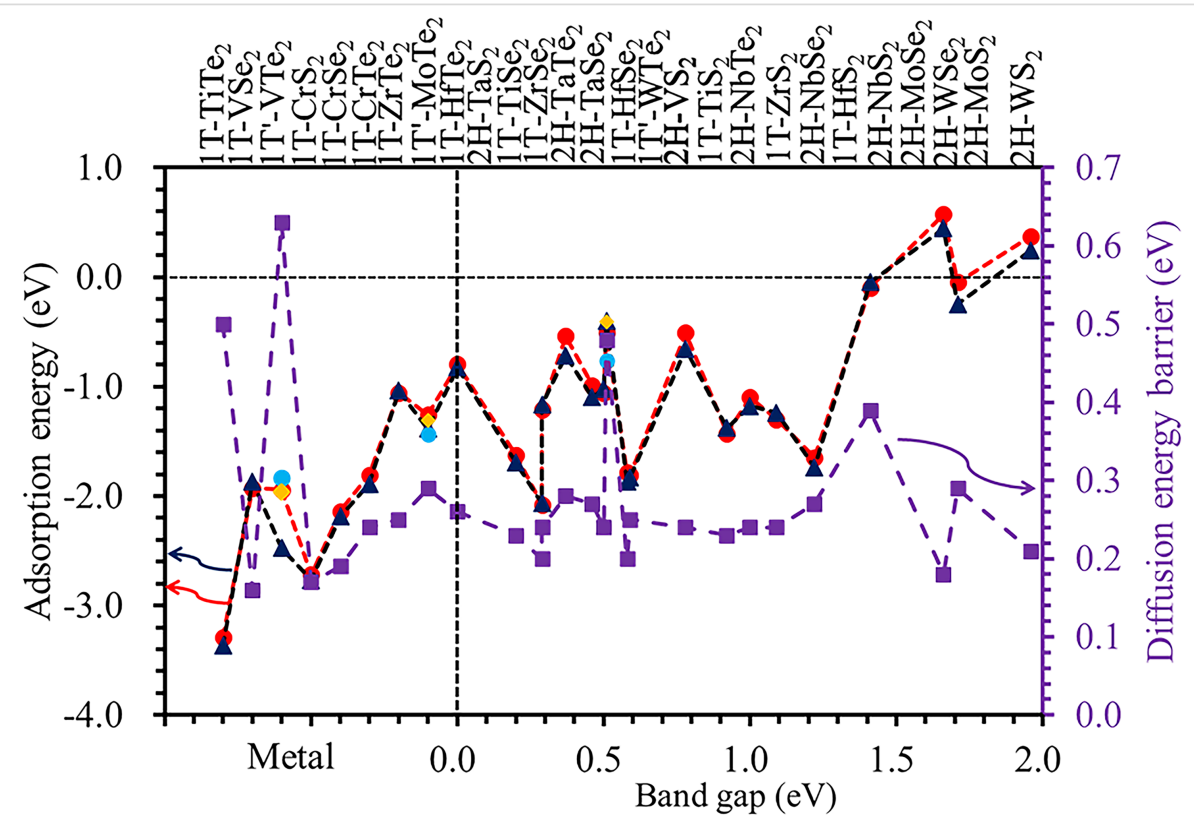

Figure 4: Adsorption energy and diffusion energy barrier for $\mathrm{Li}$ on $\mathrm{MX}_{2}$ monolayers in the stable phase.

in the $1 \mathrm{~T}$ phase, and $1 \mathrm{~T}-\mathrm{VS}_{2}$ can be stable both in the $2 \mathrm{H} / 1 \mathrm{~T}$ phase. The $2 \mathrm{H}$ phase is the stable structure for $\mathrm{MoS}_{2}, \mathrm{MoSe}_{2}$, $\mathrm{WS}_{2}$ and $\mathrm{WSe}_{2}$. The $1 \mathrm{~T}^{\prime}$ phase is the most energetically favourable for $\mathrm{VTe}_{2}, \mathrm{MoTe}_{2}$ and $\mathrm{WTe}_{2}$. The $2 \mathrm{H}$ phase shows a semiconducting behaviour, for example, $2 \mathrm{H}-\mathrm{WX}_{2}, 2 \mathrm{H}-\mathrm{NbX}_{2}$,
$2 \mathrm{H}-\mathrm{TaX}_{2}$ and $2 \mathrm{H}-\mathrm{MoX}_{2}$. The $1 \mathrm{~T}$ phase can be metallic or semiconducting, for example $1 \mathrm{~T}-\mathrm{CrX}_{2}$ shows a metallic behaviour while $1 \mathrm{~T}-\mathrm{TiX}_{2}, 1 \mathrm{~T}-\mathrm{ZrX}_{2}$ and $1 \mathrm{~T}-\mathrm{HfX}_{2}$ show semiconducting and metallic behaviour with $\mathrm{X}=\mathrm{S} / \mathrm{Se}$ and $\mathrm{X}=\mathrm{Te}$, respectively. $1 \mathrm{~T}^{\prime}-\mathrm{VTe}_{2}$ and $1 \mathrm{~T}^{\prime}-\mathrm{MoTe}_{2}$ show metallic behaviour and $1 \mathrm{~T}^{\prime}-$ 
$\mathrm{WTe}_{2}$ has a narrow bandgap of $0.50 \mathrm{eV}$. The adsorption and diffusion of lithium on the stable $\mathrm{MX}_{2}$ phase were also investigated. The results show that lithium is energetically able to adsorb on $\mathrm{MX}_{2}$ monolayers, which are semiconductors with a narrow bandgap, and on metallic materials. Lithium cannot be adsorbed on $2 \mathrm{H}-\mathrm{WS}_{2}$ and $2 \mathrm{H}-\mathrm{WSe}_{2}$, which have a large bandgap of 1.66 and $1.96 \mathrm{eV}$, respectively. The diffusion energy barrier is in the range between 0.17 and $0.63 \mathrm{eV}$ for lithium on $\mathrm{MX}_{2}$ monolayers, and most of the materials are around $0.25 \mathrm{eV}$. It is therefore concluded that most of the $\mathrm{MX}_{2}$ monolayers can be used as promising anode materials for lithium ion batteries.

\section{Simulation Details}

All the spin-polarized DFT calculations were performed with SIESTA code [62], in which norm-conserving pseudopotentials and a Perdew-Burcke-Ernzerhof functional was used to describe the electron-ion interaction and electron exchange correlation, respectively. Numerical atomic orbits were represented as double zeta basis sets plus polarization, and a cut-off energy of 250 Ry was chosen to calculate the Hamiltonian element. The Monkhorst-Pack scheme with $11 \times 11 \times 1 k$-point meshes were used for integration in the irreducible Brillouin zone for the relaxation of the primitive cell. A $2 \times 2 \times 1 k$-point mesh was used for the calculation of adsorption and diffusion of Li on a $6 \times 6 \times 1$ supercell. As the electrochemical process involves insertion of $\mathrm{Li}$ ions into anode materials with a concurrent flow of electrons to compensate charge balance, and therefore, the neutral state of Li was considered in this work. The atomic positions were relaxed by using a conjugate gradient minimization until the Hellmann-Feynman force is less than $0.02 \mathrm{eV} / \AA$ on each atom. A vacuum spacing between the slabs and its image of greater than $20 \AA$ is given to avoid the periodic image interactions. As the radii are different for different elements of $\mathrm{X}$ in $\mathrm{MX}_{2}$ monolayers (i.e., the radius increases from $\mathrm{S}$ to Te in group VI), the lattice constants and bond length of the $\mathrm{M}-\mathrm{X}$ bond will change for $\mathrm{MX}_{2}$ monolayers with different $\mathrm{X}$ elements, which can affect the adsorption and diffusion of $\mathrm{Li}$ on $\mathrm{MX}_{2}$ monolayers.

\section{Acknowledgements}

This work was financially supported by the National Natural Science Foundation of China (11474047) and the Fundamental Research Funds for the Central Universities (ZYGX2016J202). This work was carried out at National Supercomputer Center in Tianjin, and the calculations were performed on TianHe-1(A).

\section{References}

1. Goodenough, J. B.; Kim, Y. Chem. Mater. 2010, 22, 587-603. doi:10.1021/cm901452z
2. Cheng, C.; Zhou, G.; Du, J.; Zhang, H.; Guo, D.; Li, Q.; Wei, W.; Chen, L. New J. Chem. 2014, 38, 2250. doi:10.1039/c3nj01642k

3. Chen, G.; Fu, E.; Zhou, M.; Xu, Y.; Fei, L.; Deng, S.; Chaitanya, V.; Wang, Y.; Luo, H. J. Alloys Compd. 2013, 578, 349-354. doi:10.1016/j.jallcom.2013.06.042

4. Wang, L.; Dong, Z.; Wang, D.; Zhang, F.; Jin, J. Nano Lett. 2013, 13 , 6244-6250. doi:10.1021/nl403715h

5. Vasilyeva, E.; Nasibulin, A.; Tolochko, O.; Rudskoy, A.; Sachdev, A.; Xiao, X. Z. Phys. Chem. 2015, 229, 1429-1437. doi:10.1515/zpch-2015-0573

6. Yao, Q.; Huang, C.; Yuan, Y.; Liu, Y.; Liu, S.; Deng, K.; Kan, E. J. Phys. Chem. C 2015, 119, 6923-6928. doi:10.1021/acs.jpcc.5b02130

7. Kang, J.-G.; Park, J.-G.; Kim, D.-W. Electrochem. Commun. 2010, 12, 307-310. doi:10.1016/j.elecom.2009.12.025

8. Wang, Z.; Su, Q.; Deng, H. Phys. Chem. Chem. Phys. 2013, 15, 8705-8709. doi:10.1039/C3CP51167G

9. Radisavljevic, B.; Radenovic, A.; Brivio, J.; Giacometti, V.; Kis, A. Nat. Nanotechnol. 2011, 6, 147-150. doi:10.1038/nnano.2010.279

10. Lee, C.; Yan, H.; Brus, L. E.; Heinz, T. F.; Hone, J.; Ryu, S. ACS Nano 2010, 4, 2695-2700. doi:10.1021/nn1003937

11. Lauritsen, J. V.; Kibsgaard, J.; Helveg, S.; Topsøe, H.; Clausen, B. S.; Lægsgaard, E.; Besenbacher, F. Nat. Nanotechnol. 2007, 2, 53-58. doi:10.1038/nnano.2006.171

12. Liu, K.-K.; Zhang, W. J.; Lee, Y.-H.; Lin, Y.-C.; Chang, M.-T.; Su, C.-Y.; Chang, C.-S.; Li, H.; Shi, Y.; Zhang, H.; Lai, C.-S.; Li, L.-J. Nano Lett. 2012, 12, 1538-1544. doi:10.1021/nl2043612

13. Lee, H. S.; Min, S.-W.; Chang, Y.-G.; Park, M. K.; Nam, T.; Kim, H.; Kim, J. H.; Ryu, S.; Im, S. Nano Lett. 2012, 12, 3695-3700. doi:10.1021/nl301485q

14. Lee, Y.-H.; Zhang, X.-Q.; Zhang, W.; Chang, M.-T.; Lin, C.-T.; Chang, K.-D.; Yu, Y.-C.; Wang, J. T.-W.; Chang, C.-S.; Li, L.-J.; Lin, T.-W. Adv. Mater. 2012, 24, 2320-2325. doi:10.1002/adma.201104798

15. Cai, Y.; Yang, X.; Liang, T.; Dai, L.; Ma, L.; Huang, G.; Chen, W.; Chen, H.; Su, H.; Xu, M. Nanotechnology 2014, 25, 465401. doi:10.1088/0957-4484/25/46/465401

16. Xiao, J.; Choi, D.; Cosimbescu, L.; Koech, P.; Liu, J.; Lemmon, J. P. Chem. Mater. 2010, 22, 4522-4524. doi:10.1021/cm101254j

17. Liu, Y.; Zhao, Y.; Jiao, L.; Chen, J. J. Mater. Chem. A 2014, 2, 13109-13115. doi:10.1039/c4ta01644k

18. Li, Y.; Wu, D.; Zhou, Z.; Cabrera, C. R.; Chen, Z. J. Phys. Chem. Lett. 2012, 3, 2221-2227. doi:10.1021/jz300792n

19. Sun, X.; Wang, Z.; Fu, Y. Q. Sci. Rep. 2015, 5, 18712. doi:10.1038/srep18712

20. Xie, X.; Chen, S.; Sun, B.; Wang, C.; Wang, G. ChemSusChem 2015, 8, 2948-2955. doi:10.1002/cssc.201500149

21. Wang, X.; Li, G.; Seo, M. H.; Hassan, F. M.; Hoque, M. A.; Chen, Z. Adv. Energy Mater. 2015, 5, 1501106. doi:10.1002/aenm.201501106

22. Jian, Z.; Zhao, B.; Liu, P.; Li, F.; Zheng, M.; Chen, M.; Shi, Y.; Zhou, H. Chem. Commun. 2014, 50, 1215-1217. doi:10.1039/C3CC47977C

23. Hu, T.; Li, R.; Dong, J. J. Chem. Phys. 2013, 139, 174702. doi:10.1063/1.4827082

24. Song, l.; Park, C.; Choi, H. C. RSC Adv. 2015, 5, 7495-7514. doi:10.1039/C4RA11852A

25. Wypych, F.; Schöllhorn, R. J. Chem. Soc., Chem. Commun. 1992, 1386-1388. doi:10.1039/C39920001386

26. Wang, X.; Shen, X.; Wang, Z.; Yu, R.; Chen, L. ACS Nano 2014, 8 , 11394-11400. doi:10.1021/nn505501v 
27. Wang, L.; Xu, Z.; Wang, W.; Bai, X. J. Am. Chem. Soc. 2014, 136, 6693-6697. doi:10.1021/ja501686w

28. Cheng, Y.; Nie, A.; Zhang, Q.; Gan, L.-Y.; Shahbazian-Yassar, R.; Schwingenschlogl, U. ACS Nano 2014, 8, 11447-11453. doi:10.1021/nn505668c

29. Sun, X.; Wang, Z.; Li, Z.; Fu, Y.-Q. Sci. Rep. 2016, 6, 26666. doi:10.1038/srep26666

30. Lee, J. H.; Jang, W. S.; Han, S. W.; Baik, H. K. Langmuir 2014, 30 , 9866-9873. doi:10.1021/la501349k

31. Tang, Q.; Jiang, D.-e. ACS Catal. 2016, 6, 4953-4961. doi:10.1021/acscatal.6b01211

32. Yang, E.; Ji, H.; Jung, Y. J. Phys. Chem. C 2015, 119, 26374-26380. doi:10.1021/acs.jpcc.5b09935

33. Guo, H.; Lu, N.; Wang, L.; Wu, X.; Zeng, X. C. J. Phys. Chem. C 2014, 118, 7242-7249. doi:10.1021/jp501734s

34. Tibbetts, K.; Miranda, C. R.; Meng, Y. S.; Ceder, G. Chem. Mater. 2007, 19, 5302-5308. doi:10.1021/cm0715242

35. Ambrosi, A.; Sofer, Z.; Pumera, M. Chem. Commun. 2015, 51, 8450-8453. doi:10.1039/c5cc00803d

36. Li, Y.; Duerloo, K.-A. N.; Wauson, K.; Reed, E. J. Nat. Commun. 2016, 7, 10671. doi:10.1038/ncomms10671

37. Enyashin, A. N.; Yadgarov, L.; Houben, L.; Popov, I.; Weidenbach, M.; Tenne, R.; Bar-Sadan, M.; Seifert, G. J. Phys. Chem. C 2011, 115, 24586-24591. doi:10.1021/jp2076325

38. Sun, Y.; Wang, Y.; Sun, D.; Carvalho, B. R.; Read, C. G.; Lee, C.-h.; Lin, Z.; Fujisawa, K.; Robinson, J. A.; Crespi, V. H.; Terrones, M.; Schaak, R. E. Angew. Chem., Int. Ed. 2016, 55, 2830-2834. doi:10.1002/anie.201510029

39. Duerloo, K.-A. N.; Li, Y.; Reed, E. J. Nat. Commun. 2014, 5, 4214 doi:10.1038/ncomms5214

40. Reyes-Retana, J. A.; Cervantes-Sodi, F. Sci. Rep. 2016, 6, 24093. doi:10.1038/srep24093

41. Ataca, C.; Şahin, H.; Ciraci, S. J. Phys. Chem. C 2012, 116, 8983-8999. doi:10.1021/jp212558p

42. Jing, Y.; Zhou, Z.; Cabrera, C. R.; Chen, Z. J. Phys. Chem. C 2013, 117, 25409-25413. doi:10.1021/jp410969u

43. Zhang, H.; Liu, L.-M.; Lau, W.-M. J. Mater. Chem. A 2013, 1, 10821. doi:10.1039/c3ta12098h

44.Kan, M.; Wang, B.; Lee, Y.-H.; Sun, Q. Nano Res. 2015, 8, 1348-1356. doi:10.1007/s12274-014-0626-5

45. Zhuang, H. L.; Hennig, R. G. Phys. Rev. B 2016, 93, 054429. doi:10.1103/PhysRevB.93.054429

46. Ma, Y.; Dai, Y.; Guo, M.; Niu, C.; Zhu, Y.; Huang, B. ACS Nano 2012, 6, 1695-1701. doi:10.1021/nn204667z

47. Rasmussen, F. A.; Thygesen, K. S. J. Phys. Chem. C 2015, 119, 13169-13183. doi:10.1021/acs.jpcc.5b02950

48. Ding, Y.; Wang, Y.; Ni, J.; Shi, L.; Shi, S.; Tang, W. Physica B 2011, 406, 2254-2260. doi:10.1016/j.physb.2011.03.044

49. Huang, W.; Da, H.; Liang, G. J. Appl. Phys. 2013, 113, 104304 doi:10.1063/1.4794363

50. Qian, X.; Lu, J.; Fu, L.; Li, J. Science 2014, 346, 1344-1347. doi:10.1126/science.1256815

51. Mak, K. F.; Lee, C.; Hone, J.; Shan, J.; Heinz, T. F. Phys. Rev. Lett. 2010, 105, 136805. doi:10.1103/PhysRevLett.105.136805

52. Tongay, S.; Zhou, J.; Ataca, C.; Lo, K.; Matthews, T. S.; Li, J.; Grossman, J. C.; Wu, J. Nano Lett. 2012, 12, 5576-5580. doi:10.1021/nl302584w

53. Conley, H. J.; Wang, B.; Ziegler, J. I.; Haglund, R. F., Jr.; Pantelides, S. T.; Bolotin, K. I. Nano Lett. 2013, 13, 3626-3630. doi:10.1021/nl4014748
54. Ji, Q.; Zhang, Y.; Gao, T.; Zhang, Y.; Ma, D.; Liu, M.; Chen, Y.; Qiao, X.; Tan, P.-H.; Kan, M.; Feng, J.; Sun, Q.; Liu, Z. Nano Lett. 2013, 13, 3870-3877. doi:10.1021/nl401938t

55. Huang, H. H.; Fan, X.; Singh, D. J.; Chen, H.; Jiang, Q.; Zheng, W. T. Phys. Chem. Chem. Phys. 2016, 18, 4086-4094. doi:10.1039/c5cp06706e

56. Sik Hwang, W. S.; Remskar, M.; Yan, R.; Protasenko, V.; Tahy, K.; Doo Chae, S.; Zhao, P.; Konar, A.; Xing, H.; Seabaugh, A.; Jena, D. Appl. Phys. Lett. 2012, 101, 013107. doi:10.1063/1.4732522

57. Gutiérrez, H. R.; Perea-López, N.; Elias, A. L.; Berkdemir, A.; Wang, B.; Lv, R.; López-Urías, F.; Crespi, V. H.; Terrones, H.; Terrones, M. Nano Lett. 2013, 13, 3447-3454. doi:10.1021/nl3026357

58. Kozawa, D.; Kumar, R.; Carvalho, A.; Kumar Amara, K.; Zhao, W.; Wang, S.; Toh, M.; Ribeiro, R. M.; Castro Neto, A. H.; Matsuda, K.; Eda, G. Nat. Commun. 2014, 5, 4543. doi:10.1038/ncomms5543

59. Nasr Esfahani, D.; Leenaerts, O.; Sahin, H.; Partoens, B.; Peeters, F. M. J. Phys. Chem. C 2015, 119, 10602-10609. doi:10.1021/jp510083w

60. Henkelman, G.; Jóhannesson, G.; Jónsson, H. Methods for Finding Saddle Points and Minimum Energy Path. In Theoretical Methods in Condensed Phase Chemistry; Schwartz, S. D., Ed.; Springer: Amsterdam, Netherlands, 2002; pp 269-302.

61. Wang, D.; Liu, L. M.; Zhao, S. J.; Hu, Z. Y.; Liu, H. J. Phys. Chem. C 2016, 120, 4779-4788. doi:10.1021/acs.jpcc.5b11677

62. Soler, J. M.; Artacho, E.; Gale, J. D.; García, A.; Junquera, J.; Ordejón, P.; Sánchez-Portal, D. J. Phys.: Condens. Matter 2002, 14, 2745-2779. doi:10.1088/0953-8984/14/11/302

\section{License and Terms}

This is an Open Access article under the terms of the Creative Commons Attribution License (http://creativecommons.org/licenses/by/4.0), which permits unrestricted use, distribution, and reproduction in any medium, provided the original work is properly cited.

The license is subject to the Beilstein Journal of

Nanotechnology terms and conditions:

(http://www.beilstein-journals.org/bjnano)

The definitive version of this article is the electronic one which can be found at: doi:10.3762/bjnano.8.270 